\title{
Paternal intake of folate and vitamins B6 and B12 before conception and risk of childhood acute lymphoblastic leukemia
}

Helen D Bailey ${ }^{1,2}$, Margaret Miller ${ }^{3}$, Kathryn R. Greenop ${ }^{2}$, Carol Bower ${ }^{2}$, John Attia ${ }^{4,5}$, Glenn M Marshall $^{6}$, Bruce K Armstrong ${ }^{7,8}$, Elizabeth Milne ${ }^{2}$ for the Aus-ALL Consortium

${ }^{1}$ International Agency for Research on Cancer (IARC), Section of Environment and Radiation, 150 Cours Albert Thomas, 69372 Lyon Cedex 08, France

${ }^{2}$ The University of Western Australia, Telethon Kids Institute, Perth, Western Australia, Australia

${ }^{3}$ Edith Cowan University, Child Health Promotion Research Centre, School of Exercise, and Health Sciences, Joondalup, Western Australia, Australia

${ }^{4}$ University of Newcastle, Faculty of Health, School of Medicine and Public Health, Newcastle, NSW

${ }^{5}$ Hunter Medical Research Institute, John Hunter Hospital, New Lambton, NSW, Australia.

${ }^{6}$ Sydney Children’s Hospital, Kids Cancer Centre, Children’s Cancer Institute Australia for Medical Research, University of New South Wales, Sydney, New South Wales, Australia

${ }^{7}$ University of Sydney, Sydney School of Public Health, New South Wales, Australia

${ }^{8}$ Sax Institute, Ultimo, NSW, Australia. 
Address for correspondence: Helen Bailey, Section of Environment and Radiation,

International Agency for Research on Cancer, 150 Cours Albert Thomas, Lyon 69372 Cedex 08,

France. Telephone: [+33] (0)4 7273 8310. Fax: [+33] (0)4 72738320

Email: baileyh@fellows.iarc.fr; helenb@ichr.uwa.edu

Main text word count: $3191(6.8 .14)$

Abstract word count: 242 (6.8.14)

\section{Number of tables: 5}

Number of figures: 0

No of references: 37

\section{ABBREVIATIONS}

ALL Acute lymphoblastic leukemia

Aus-ALL Australian Study of Causes of Acute Lymphoblastic Leukaemia in Children

CI confidence interval

DFE Dietary Folate Equivalents

FFQ food frequency questionnaire. 
OR odds ratio

RDD random digit dialling 


\section{ABSTRACT}

Purpose: We investigated whether paternal dietary intake of folate before conception is associated with the risk of childhood acute lymphoblastic leukemia (ALL) in a nation-wide casecontrol study.

Methods: Data on dietary folate intake during the six months before the child's conception were collected from 285 case fathers and 595 control fathers using a dietary questionnaire. Nutrient intake was quantified using a customized computer software package based on Australian food composition databases. Data on folate intake were analyzed using unconditional logistic regression, adjusting for study matching variables, total energy and potentially confounding variables. In a subset of 229 cases and 420 controls, data on vitamin B6 and vitamin B12 intake were also analyzed.

Results: No consistent associations were seen with paternal dietary intake of folate or vitamin B6. Higher levels of paternal dietary vitamin B12 appeared to be associated with an increased risk of childhood ALL, with those in the highest tertile of consumption having an OR of 1.51 (0.97, 2.36). The use of supplements containing folate, vitamins B6 or B12 was rare.

Conclusions: We did not find any biologically plausible evidence that paternal nutrition in the period leading up to conception was associated with childhood ALL. Our finding for vitamin B12 may be a chance finding, given the number of analyses performed, or be attributable to participation bias because parents with a tertiary education had the lowest level of B12 intake and tertiary education was more common among control than case parents. 
Keywords: Epidemiology, child, leukemia, folate, Vitamin B6, Vitamin B12,

\section{INTRODUCTION}

Acute lymphoblastic leukemia (ALL), the most common childhood malignancy, occurs mainly in children under the age of five years, suggesting a role for parental exposures before birth. Past studies have suggested that maternal diet [1-5] or use of dietary supplements [6-8] during pregnancy could affect the risk of ALL in the offspring. There has been little research published about possible effects of paternal diet and supplement use; we identified only one study of paternal use of vitamin supplements in the year before the child's conception, which had a null finding [9], and no studies of paternal diet. However, it is biologically plausible that paternal diet is associated with germ cell damage and thus with adverse outcomes in the offspring [10]. For example, seminal fluid folate levels were found to be inversely correlated with levels of sperm DNA damage [11], and low dietary intake of folate was associated with sperm aneuploidy in healthy men [12]. A protective effect of folate is plausible due to its role in DNA methylation, synthesis and repair [13]. Folate provides 5-methyltetrahydrofolate for the methylation pathway from homocysteine to S-adenosylmethionine, the principal methyl donor in DNA methylation. DNA methylation affects gene expression and can silence cell-cycle-regulating genes via methylation of specific promoter region CpG. In addition, folate is essential for normal DNA synthesis and repair; in the form of 5,10-methylenetetrahydrofolate, it is the one-carbon donor in the synthesis of thymidylate. Vitamin B6 (B6) and vitamin B12 (B12) are essential cofactors in these one-carbon metabolic pathways [5]. 
In this paper, we investigate whether paternal dietary or supplemental folate intake in the time leading up to conception is associated with risk of ALL in the offspring, using data from The Australian Study of Causes of Acute Lymphoblastic Leukaemia in Children (Aus-ALL). We also report results for B6 and B12.

\section{MATERIALS AND METHODS}

\section{Participants and recruitment}

Aus-ALL was a national, population-based case-control study that prospectively recruited 416 ALL cases and 1,361 controls over five years (mid 2003-2007). Its aim was to investigate dietary, environmental and genetic risk factors for ALL and their interactions. The study design has been described previously [14-16]. Briefly, only children whose biological mothers were available and had adequate English skills were eligible for inclusion in the study. However, families where the biological father was not available were eligible for inclusion. Case families were identified and recruited through all ten pediatric oncology centers in Australia. Cases were eligible for inclusion in the study if they were diagnosed between $1^{\text {st }}$ July 2003 and $31^{\text {st }}$ December 2006 and achieved initial remission. Controls were frequency matched to cases on age (within 1 year), sex and State of residence in a ratio of approximately 3:1. The controls were prospectively recruited by national random digit dialling (RDD) between August 2003 and October 2006 [14]. The study had the approval of ten hospital Human Research Ethics Committees.

Data collection 
Fathers completed food frequency questionnaires (FFQs) about their diet and use of dietary supplements during the six months before conception. To help fathers recall the correct time period, at the beginning of the FFQ they were asked to record the child's month and year of birth and then to note the beginning and end dates of the pregnancy, and the beginning and end dates six months before this. These FFQs were based on those developed by the Australian Commonwealth Scientific and Research Organization [17]. For all foods, a standard serving size was given and fathers were asked to list the frequency of consumption and the number of standard serves usually consumed at any one time. Specific information about the brand was also collected for types of foods that were eligible to have been fortified with folic acid in the period of interest. The initial FFQ listed foods reflecting the total diet, but during the study the food lists were reduced to focus on foods with significant 'folate, B6 and B12' or just 'folate' contribution to reduce respondent burden. Parents also completed questionnaires about demographics and the environmental exposures of interest, including paternal alcoholic drink consumption in the year before conception.

\section{Assessment of nutrient intake}

Energy and nutrient intake was quantified using a customized computer software package that merged data from Australian food composition databases (AUS-NUT 07 [18] for folate and energy and NUTTAB 2010 [19] for B6 and B12) with the FFQ serving size and individual frequency of consumption and calculated the sum over all foods. Based on biological plausibility, we excluded anyone with a total daily energy intake of less than 4,000 kJ (six cases and nine controls). 
At the time of the study, voluntary folic acid fortification of certain food categories (for example, breakfast cereals and mueslis; breads; fruit and vegetable juices; and yoghurts) was allowed. Information about the amount of supplemental folic acid in individual products was collected from manufacturers and food labels and added to the analysis program. Food folate composition was expressed as Dietary Folate Equivalents (DFE), which allows for the higher bioavailability of folic acid than food folate: DFE $=$ food folate $+(1.7 \mathrm{x}$ folic acid $)$ [20].

\section{Statistical analysis}

A calibration equation, based on those who did the full diet FFQ, was used to convert the data from those who did the reduced versions of the FFQ to reflect the full diet. Data on folate, B6 and B12 were right skewed, and so were log transformed. These values were then adjusted for energy using methods described elsewhere [21]. Energy-adjusted folate, B6 and B12 values were grouped according to tertiles, with the lowest tertile used as the reference group.

A binary variable for the use of a supplement containing any folic acid, B6 or B12 (use versus no use) at any time in the year before conception was created; these three micronutrients were combined into a single variable as all were found in almost all products containing any one of them. Non-use was the reference group for analyses.

Odds ratios (OR) and 95 percent confidence intervals (95\% CI) were estimated using unconditional logistic regression (SAS version 9.2, SAS Institute Inc, Cary, NC, USA) to investigate the association between energy-adjusted paternal dietary folate intake in the six months before conception and risk of ALL. All models were adjusted for study matching factors: age, sex and State of residence. The following variables were considered a priori to be potential 
confounders of the association between dietary folate and risk of ALL were assessed for inclusion in the models: highest parental education, paternal age group, birth order, year of diagnosis (or agreement for controls), paternal smoking in the conception year, FFQ version, ethnicity, gestation, plurality, large for gestational age, birth defect, area based measure of socioeconomic status, paternal alcohol consumption, and birth year. Those included in the final model on the basis that they met the empirical criteria for confounding (i.e., they were associated with exposure in the controls and case/control status or study participation) were: highest parental education, paternal age group, birth order, year of diagnosis (or agreement for controls), paternal smoking in the conception year and FFQ version.

The final model also included B6, B12 and folic acid supplement use and, for those who did the versions of the FFQ that included foods containing B6 and B12, energy-adjusted values of all nutrients were added to the model. Because alcohol is known to disrupt folate metabolism [22], additional analyses were undertaken stratified by level of paternal alcohol intake in the year before conception; based on intake above or below median weekly consumption among controls (eight drinks per week). Stratified analyses were also undertaken based on the child's age at the censoring date (diagnosis for cases and agreement for controls) (less than five years of age and 5 years or more) as any effect of folate might be seen more strongly among those children who were diagnosed with ALL early in life. Because the proportions of cases and controls who did each version of the FFQ were different, we also stratified the folate analyses by FFQ version.

As children with some birth defects (for example Down syndrome) have higher rates of ALL than other children, analyses were repeated excluding all children with birth defects (14 cases and 19 controls). 
As some drugs can inhibit the absorption of folate such as anti-inflammatories [23] and anti-convulsants [24], analyses were also repeated excluding those fathers who took these drugs or had missing data about them (21 cases and 19 controls)

\section{RESULTS}

We were notified of 519 eligible ALL cases, and parents of 416 (80\%) cases consented to participate in the study. Of these, 296 case fathers completed and returned a FFQ. After excluding 11 with poor quality data, 285 of these were included in the final dietary folate analyses (68.5\% of consenting and $54.9 \%$ of eligible). Of the 1,361 control families recruited to the study, 618 fathers returned a FFQ. After excluding 17 fathers with poor quality data and six where ethnicity could not be determined, 595 (43.7\%) control fathers were included in the final analyses. For analyses restricted to versions with B6 and B12 data, there were 229 case and 420 control fathers.

The distribution of demographic and other variables of interest were generally similar in participating cases and controls (Table 1); however, higher proportions of cases were first-born, had a father aged 30 years or less, and had a father who smoked in the conception year. Control parents were more likely to have completed university or college, and controls fathers were more likely to have completed the full version of the FFQ. The same pattern of distribution was also seen in the subset included in the B6 and B12 analyses (results not shown). The ranges of daily dietary intakes are shown in Table 2.

There was little evidence of an association between risk of ALL and paternal dietary folate intake among all participants combined (Table 3) or only participants with B6 and B12 
dietary estimates (Supplementary Table 1). There was also little evidence of an association with dietary B6 intake (Table 3). The OR for the highest level of vitamin B12 intake was 1.51 (95\% CI 0.97, 2.36) (Table 3), and the $P$ value for trend was 0.07. Paternal use of supplements containing folic acid and/or vitamins B6 or B12 was uncommon and as a result the ORs were imprecise (Table 3).

When the analyses were stratified by the child's age at the censoring date, the OR for the highest level of folate intake was 0.63 (95\% CI 0.32, 1.12) among children aged five years or more, and 1.12 (95\% CI 0.67, 1.88) among younger children (Table 4). The ORs for B6 showed weak evidence of a protective effect in those aged under five, but not those who were older. The OR for B12 intake appeared to be somewhat higher among children under the age of five years $(P$ value for trend 0.06) (Table 4).

When the analyses were stratified by paternal alcohol consumption in the year before conception, there was a weak inverse association with folate among those who drank less than eight drinks a week that was not seen among those in the higher alcohol consumption group (Table 5). The ORs for B6 suggested weak evidence of a protective effect in those in the low alcohol consumption group, but not in the higher consumption group. The patterns for B12 were similar in low and high alcohol consumers. In all the stratified analyses, the numbers in many cells were relatively small. When the folate analyses were stratified by FFQ version, there was little difference in the findings (results not shown). Exclusion of children with any birth defect had little effect on the findings as did excluding fathers who took drugs that inhibited folate absorption or potentially inhibited (or who had missing data about this) (results not shown). 


\section{Discussion}

In this study, the level of paternal dietary folate or B6 in the six months prior to conception did not appear to be associated with ALL risk. The ORs for B12 provide weak evidence that paternal diet high in this vitamin may be associated with an increased risk of ALL, but as we discuss below, this may be a spurious finding. The consumption of supplements containing folic acid and/or vitamins B6 and/or B12 was not common, thus we cannot draw any conclusions regarding an association between their use and risk of childhood ALL.

Vitamin B12 is produced in the gastrointestinal tracts of animals by bacteria and then absorbed by the host animal [25]. Therefore, it only found in animal tissues such as liver, red meat, chicken, eggs and dairy products and does not naturally occur in bioactive forms in plant foods.[25]. We were unable to identify previous studies of specific micronutrients in paternal diet and risk of ALL. The only previous investigation of paternal diet and risk of childhood cancer was of retinoblastoma, and it had inconsistent findings [26] in relation to foods containing B12, such as meats, milk, fish and eggs. The findings in relation to dietary B12 and other cancers have been inconsistent. Higher dietary B12 levels have been associated with increased risk of breast [27], pancreatic [28], prostate [29], and gastric/ oesophageal [30] cancers but decreased risk of colorectal [31], and bladder [32] cancers. We cannot find any biological mechanism to explain an association between paternal dietary B12 and ALL in the offspring. Others have hypothesized that B12 intake may be a proxy for another factor associated with B12-containing foods, but we were unable to address this possibility.

Other plausible explanations for the association we observed for vitamin B12 include participation bias. Dietary B12 varied by parental education among the controls; among those with a university or college education, $30 \%$ were in the highest tertile of B12 consumption compared to $38 \%$ among those with less education. Using area-based measures, we have 
previously shown that our control parents were of higher socio-economic status than the general Australian population [14]. Therefore, participation bias may have led to an underestimation of vitamin B12 intake among control fathers and thus biased the ORs upwards. Although we adjusted for parental education in the analytical models, there may have been residual confounding. Alternately, the weakness and relative imprecision of the association with B12 could indicate a chance finding, given the number of analyses. There is some previous evidence of an association between socio-economic status and vitamin B12 status [33] or consumption of foods high in B12 [34,35]. In a dietary survey of Irish adults, vitamin B12 intake was inversely associated with social class and education among women, with a suggested similar trend in men [33]. Similarly, men of low socio-economic status consumed more meat and meat products and less vegetable proteins in a Dutch survey [34], while in the UK, men with lower education and of lower social class ate more red and processed meats [35].

Aus-ALL had some strengths and limitations. Cases were ascertained from oncology centers that treat virtually all children in Australia diagnosed with ALL, and $80 \%$ of eligible parents agreed to participate; $70 \%$ of eligible controls recruited by RDD also agreed to participate, although the true level of agreement may be closer to $55 \%$ when account is taken of eligible controls in homes where the RDD calls were never answered [14]. However, participation was based on the availability of the biological mother, not the father. Thus, about $16 \%$ of case fathers and $14 \%$ control fathers did not participate. The FFQ was only sent to participating control families once the initial exposure questionnaire was returned. By contrast, case families were sent all questionnaires at the same time. The same differences in the demographic characteristics of the cases and controls, namely control fathers being older and having higher levels of education than cases was seen in investigations using the larger sample of 
389 cases and 876 controls who returned the initial exposure questionnaire[36]. The proportion of both case and control parents with a tertiary education in the larger sample was $42.7 \%$ and 53.3\% [36] compared to the $46.7 \%$ and $58.2 \%$ in these current analyses. As part of our investigations of the representativeness of the Aus-ALL controls using area based measures, we also have previously found that those who returned the FFQs were of higher economic status than those who returned the initial questionnaire [14], thus compounding the already existing potential for participation bias.

In efforts to improve its completion rate, the FFQ was changed several times during the study, thus B6 and B12 data was not available for some fathers (20\% of cases and $29 \%$ of controls) who did the FFQ. It is possible that the B6 and B12 results may have been different in those for whom intake was not assessed, but similar dietary folate results suggests this is not the case. Likewise, similar dietary folate findings for each FFQ version and the whole sample is reassurance that the differing proportions of cases and controls who did the different versions of the FFQ did not affect the validity of the findings. In addition, for each FFQ version, among those sent the FFQ, a similar proportion of case and control fathers returned it, although the response was lower for the full version ( $42 \%$ of cases and $40 \%$ of controls) compared to the 'Folate' foods version (72\% and 76\%, respectively) and 'Folate, B6 and B12' foods version (76\% and $80 \%$ respectively).

There is evidence that an FFQ designed to estimate dietary folate and other B vitamins is a suitable measure of current intake when compared with multiple 24-hour food intake interviews and plasma levels [37]. However there is likely to be a degree of measurement error in this study, as the time period of interest was up to 16 years earlier for some fathers and this could 
explain the differences we observed between the $54 \%$ of fathers whose children were aged under five years and those whose children were older than five years. Recall bias is always a potential problem in case-control studies, and there was the possibility of case fathers thinking more deeply about their diet when doing the FFQ. However, the FFQ contained a long list of foods, with no indication of what particular nutrient we were studying, or what level of consumption was considered 'normal' for each food. If recall bias played a part in our findings, one would expect elevated ORs for all nutrients, but this was not the case. As there has been relatively little research into paternal diet and childhood cancer, there is no specific focus for recall bias, and any error in reporting dietary vitamin intake is likely to be non-differential between cases and controls.

In conclusion, our finding of an association between a paternal diet high in B12 in the six months prior to conception and the risk of ALL in the offspring may be due to participation bias or chance. The level of dietary intake of folate or B6 did not appear to have any impact on the risk of ALL, while it was not possible to draw any firm conclusions about the impact of using folate, B6 or B12 supplements. While it is biologically plausible that paternal nutrition around conception could be associated with ALL in the offspring, we found little evidence in support of it.

\section{Conflict of Interest}

The authors declare no conflict of interest. Aus-ALL was funded by The National Health and Medical Research Council (NHMRC) Grant 254539. Helen Bailey was supported by NHMRC Post Graduate Scholarship 513934, Elizabeth Milne by NHMRC Career Development Award 513910 and Carol Bower by NHMRC Research Fellowship 634341. 


\section{Acknowledgements}

The Aus-ALL consortium conducted the study and the Telethon Kids Institute (Formally Telethon Institute for Child Health Research; TICHR), University of Western Australia, was the coordinating centre. Bruce K Armstrong (Sydney School of Public Health), Elizabeth Milne (TICHR), Frank M van Bockxmeer (Royal Perth Hospital), Michelle Haber (Children’s Cancer Institute Australia), Rodney J Scott (University of Newcastle), John Attia (University of Newcastle), Murray D Norris (Children's Cancer Institute Australia), Carol Bower (TICHR), Nicholas H de Klerk (TICHR), Lin Fritschi (WA Institute for Medical Research), Ursula R Kees (TICHR), Margaret Miller (Edith Cowan University), Judith R Thompson (WA Cancer Registry) were the research investigators and Helen D Bailey (TICHR) was the project coordinator. The clinical investigators were: Frank Alvaro (John Hunter Hospital, Newcastle); Catherine Cole (Princess Margaret Hospital for Children, Perth); Luciano Dalla Pozza (Children’s Hospital at Westmead, Sydney); John Daubenton (Royal Hobart Hospital, Hobart); Peter Downie (Monash Medical Centre, Melbourne); Liane Lockwood, (Royal Children’s Hospital, Brisbane); Maria Kirby (Women's and Children’s Hospital, Adelaide); Glenn Marshall (Sydney Children’s Hospital, Sydney); Elizabeth Smibert (Royal Children’s Hospital, Melbourne); Ram Suppiah, (previously Mater Children's Hospital, Brisbane). The authors wish to acknowledge the contribution made by our Clinical Co-Investigators and Clinical Research Associates who recruited and cared for study patients at each participating hospital, and Mr Peter Cosgrove for programming the estimation of dietary intake from the food frequency questionnaires. The authors also thank the parents and children who participated in Aus-ALL. 


\section{References}

1. Ross JA(1998) Maternal diet and infant leukemia: a role for DNA topoisomerase II inhibitors? Int J Cancer Suppl 11: 26-8.

2. Spector LG, Xie Y, Robison LL et al.(2005) Maternal diet and infant leukemia: the DNA topoisomerase II inhibitor hypothesis: a report from the children's oncology group. Cancer Epidemiol Biomarkers Prev 14: 651-5.

3. Petridou E, Koussouri M, Toupadaki N et al.(1998) Diet during pregnancy and the risk of cerebral palsy. Br J Nutr 79: 407-12.

4. Jensen CD, Block G, Buffler P, Ma X, Selvin S, Month S(2004) Maternal dietary risk factors in childhood acute lymphoblastic leukemia (United States). Cancer Causes Control 15: 559-70.

5. Selhub J(2002) Folate, vitamin B12 and vitamin B6 and one carbon metabolism. J Nutr Health Aging 6: 39-42.

6. Goh YI, Bollano E, Einarson TR, Koren G(2007) Prenatal multivitamin supplementation and rates of pediatric cancers: a meta-analysis. Clin Pharmacol Ther 81: 685-91.

7. Schuz J, Weihkopf T, Kaatsch P(2007) Medication use during pregnancy and the risk of childhood cancer in the offspring. Eur J Pediatr 166: 433-41.

8. Thompson JR, Gerald PF, Willoughby ML, Armstrong BK(2001) Maternal folate supplementation in pregnancy and protection against acute lymphoblastic leukaemia in childhood: a case-control study. Lancet 358: 1935-40.

9. Wen WQ, Shu XO, Potter JD et al.(2002) Parental medication use and risk of childhood acute lymphoblastic leukemia. Cancer 95: 1786-94.

10. Mayr CA, Woodall AA, Ames BN (2001) DNA damage to sperm from micronutrient deficiency may increase the risk of defects and cancer in offspring. In: Bendich A, Declebaum RJ, eds. Preventative medicine; the comprehensive guid for health professionals. Totowa, NJ: Humama Press, pp. 373-386.

11. Boxmeer JC, Smit M, Utomo E et al.(2009) Low folate in seminal plasma is associated with increased sperm DNA damage. Fertil Steril 92: 548-56.

12. Young SS, Eskenazi B, Marchetti FM, Block G, Wyrobek AJ(2008) The association of folate, zinc and antioxidant intake with sperm aneuploidy in healthy non-smoking men. Hum Reprod 23: 1014-22.

13. Kim YI(1999) Folate and carcinogenesis: evidence, mechanisms, and implications. $J$ Nutr Biochem 10: 66-88. 
14. Bailey HD, Milne E, de Klerk N et al.(2010) Representativeness of child controls recruited by random digit dialling. Paediatr Perinat Epidemiol 24: 293-302.

15. Bailey HD, Miller M, Langridge A et al.(2012) Maternal Dietary Intake of Folate and Vitamins B6 and B12 During Pregnancy and the Risk of Childhood Acute Lymphoblastic Leukemia. Nutr Cancer 64: 1122-30.

16. Bunin GR, Li Y, Ganguly A, Meadows AT, Tseng M(2013) Parental nutrient intake and risk of retinoblastoma resulting from new germline RB1 mutation. Cancer Causes Control 24: 343-55.

17. Lassale C, Guilbert C, Keogh J, Syrette J, Lange K, Cox DN(2009) Estimating food intakes in Australia: validation of the Commonwealth Scientific and Industrial Research Organisation (CSIRO) food frequency questionnaire against weighed dietary intakes. $J$ Hum Nutr Diet 22: 559-66.

18. Food Standards Australia New Zealand (2007) AUSNUT 2007.

19. Food Standards Australia New Zealand (2011) NUTTAB 2010: Australian Food Composition Tables.

20. Bailey LB(1998) Dietary reference intakes for folate: the debut of dietary folate equivalents. Nutr Rev 56: 294-9.

21. Willett W, Stampfer MJ(1986) Total energy intake: implications for epidemiologic analyses. Am J Epidemiol 124: 17-27.

22. Halsted CH, Villanueva JA, Devlin AM, Chandler CJ(2002) Metabolic interactions of alcohol and folate. $J$ Nutr 132: 2367S-72S.

23. Baggott JE, Morgan SL, Ha T, Vaughn WH, Hine RJ(1992) Inhibition of folate-dependent enzymes by non-steroidal anti-inflammatory drugs. Biochem J 282 ( Pt 1): 197-202.

24. Linnebank M, Moskau S, Semmler A et al.(2011) Antiepileptic drugs interact with folate and vitamin B12 serum levels. Ann Neurol 69: 352-9.

25. O'Leary F, Samman S(2010) Vitamin B12 in health and disease. Nutrients 2: 299-316.

26. Bunin GR, Tseng M, Li Y, Meadows AT, Ganguly A(2012) Parental diet and risk of retinoblastoma resulting from new germline RB1 mutation. Environ Mol Mutagen 53: 45161.

27. Bassett JK, Baglietto L, Hodge AM et al.(2013) Dietary intake of B vitamins and methionine and breast cancer risk. Cancer Causes Control 24: 1555-63.

28. Gong Z, Holly EA, Bracci PM(2009) Intake of folate, vitamins B6, B12 and methionine and risk of pancreatic cancer in a large population-based case-control study. Cancer Causes Control 20: 1317-25. 
29. Weinstein SJ, Stolzenberg-Solomon R, Pietinen P, Taylor PR, Virtamo J, Albanes D(2006) Dietary factors of one-carbon metabolism and prostate cancer risk. Am J Clin Nutr 84: 92935.

30. Mayne ST, Risch HA, Dubrow R et al.(2001) Nutrient intake and risk of subtypes of esophageal and gastric cancer. Cancer Epidemiol Biomarkers Prev 10: 1055-62.

31. Kune G, Watson L(2006) Colorectal cancer protective effects and the dietary micronutrients folate, methionine, vitamins B6, B12, C, E, selenium, and lycopene. Nutr Cancer 56: 11-21.

32. Wu JW, Cross AJ, Baris D et al.(2012) Dietary intake of meat, fruits, vegetables, and selective micronutrients and risk of bladder cancer in the New England region of the United States. Br J Cancer 106: 1891-8.

33. Friel S, Kelleher CC, Nolan G, Harrington J(2003) Social diversity of Irish adults nutritional intake. Eur J Clin Nutr 57: 865-75.

34. Hulshof KF, Brussaard JH, Kruizinga AG, Telman J, Lowik MR(2003) Socio-economic status, dietary intake and 10 y trends: the Dutch National Food Consumption Survey. Eur $J$ Clin Nutr 57: 128-37.

35. Aston LM, Smith JN, Powles JW(2013) Meat intake in Britain in relation to other dietary components and to demographic and risk factor variables: analyses based on the National Diet and Nutrition Survey of 2000/2001. J Hum Nutr Diet 26: 96-106.

36. Bailey HD, Milne E, de Klerk NH et al.(2011) Exposure to house painting and the use of floor treatments and the risk of childhood acute lymphoblastic leukemia. Int J Cancer 128: 2405-14.

37. Johansson I, Van GB, Hultdin J, Johansson M, Hallmans G, Stattin P(2010) Validity of food frequency questionnaire estimated intakes of folate and other B vitamins in a region without folic acid fortification. Eur J Clin Nutr 64: 905-13. 
Table 1. Characteristics of cases and controls completing an FFQ in the Australian Study of Causes of Acute Lymphoblastic Leukaemia in Children, 2003-2007.

\begin{tabular}{|c|c|c|c|c|}
\hline & \multicolumn{2}{|c|}{ Cases $(n=285)$} & \multicolumn{2}{|c|}{ Controls $(n=595)$} \\
\hline & $\mathrm{n}$ & $\%$ & $\mathrm{n}$ & $\%$ \\
\hline \multicolumn{5}{|l|}{ Sex } \\
\hline Boys & 149 & 52.3 & 313 & 52.6 \\
\hline Girls & 136 & 47.7 & 282 & 46.3 \\
\hline \multicolumn{5}{|l|}{ Age } \\
\hline $0-1$ & 24 & 8.4 & 53 & 8.9 \\
\hline $2-4$ & 130 & 45.6 & 273 & 45.9 \\
\hline $5-9$ & 81 & 28.4 & 191 & 32.1 \\
\hline $10-14$ & 50 & 17.5 & 78 & 13.1 \\
\hline \multicolumn{5}{|l|}{ State of residence } \\
\hline NSW/ACT & 88 & 30.9 & 181 & 30.4 \\
\hline VIC/TAS & 89 & 31.2 & 170 & 28.6 \\
\hline $\mathrm{SA} / \mathrm{NT}$ & 32 & 11.2 & 57 & 9.6 \\
\hline WA & 26 & 9.1 & 67 & 11.3 \\
\hline QLD & 50 & 17.5 & 120 & 20.2 \\
\hline \multicolumn{5}{|l|}{ Birth order } \\
\hline 1 & 144 & 50.5 & 244 & 41.0 \\
\hline 2 & 82 & 28.8 & 207 & 34.8 \\
\hline $3+$ & 59 & 20.7 & 144 & 24.2 \\
\hline \multicolumn{5}{|l|}{ Gestation (binary) } \\
\hline Term (37 weeks+) & 267 & 93.7 & 554 & 93.1 \\
\hline Pre-term (<37 weeks) & 17 & 6.0 & 39 & 6.6 \\
\hline Child had a birth defect & 14 & 4.9 & 19 & 3.2 \\
\hline \multicolumn{5}{|l|}{ Multiple birth } \\
\hline No, single birth & 280 & 98.2 & 580 & 97.5 \\
\hline Yes, multiple birth & 5 & 1.8 & 15 & 2.5 \\
\hline \multicolumn{5}{|l|}{ Birth Weight } \\
\hline$<3000 \mathrm{~g}$ & 48 & 16.8 & 108 & 18.2 \\
\hline $3000-<4000 g$ & 193 & 67.7 & 404 & 67.9 \\
\hline$>4000 \mathrm{~g}$ & 44 & 15.4 & 82 & 13.8 \\
\hline Large for gestational age & 40 & 14.0 & 80 & 13.4 \\
\hline \multicolumn{5}{|l|}{$\begin{array}{l}\text { Year of diagnosis/FFQ } \\
\text { completion }\end{array}$} \\
\hline 2003-2004 & 140 & 49.1 & 312 & 52.4 \\
\hline 2005-2006 & 145 & 50.9 & 283 & 47.6 \\
\hline \multicolumn{5}{|l|}{$\begin{array}{l}\text { Highest level of education of } \\
\text { either parent }\end{array}$} \\
\hline $\begin{array}{l}\text { Did not complete secondary } \\
\text { school }\end{array}$ & 30 & 10.5 & 30 & 5.0 \\
\hline $\begin{array}{l}\text { Completed secondary school } \\
\text { and/or trade } \\
\text { qualification }\end{array}$ & 122 & 42.8 & 219 & 36.8 \\
\hline
\end{tabular}




\begin{tabular}{|c|c|c|c|c|}
\hline $\begin{array}{l}\text { University/college } \\
\text { Ethnicity }^{a}\end{array}$ & 133 & 46.7 & 346 & 58.2 \\
\hline European ethnicity & 242 & 84.9 & 531 & 89.2 \\
\hline At least 50\% European & 32 & 11.2 & 50 & 8.4 \\
\hline $\begin{array}{l}\text { At least 50\% non-European, and } \\
\text { not known 286if 50\% } \\
\text { European }\end{array}$ & 11 & 3.9 & 14 & 2.4 \\
\hline Household income & & & & \\
\hline$<\$ 40,000$ & 54 & 18.9 & 77 & 12.9 \\
\hline$\$ 40,001-70,000$ & 90 & 31.6 & 202 & 33.9 \\
\hline$\$ 70,001-100,000$ & 71 & 24.9 & 163 & 27.4 \\
\hline$>\$ 100,000$ pa & 70 & 24.6 & 152 & 25.5 \\
\hline Father's age at child's birth & & & & \\
\hline 30 years or less & 118 & 41.4 & 192 & 32.3 \\
\hline 31 to 35 years & 93 & 32.6 & 220 & 37.0 \\
\hline More than 35 years & 74 & 26.0 & 182 & 30.6 \\
\hline $\begin{array}{c}\text { Father's weekly alcohol intake in } \\
\text { year before conception }\end{array}$ & & & & \\
\hline$<8$ drinks per week & 158 & 55.4 & 328 & 55.1 \\
\hline 8 drinks or more per week & 123 & 43.2 & 265 & 44.5 \\
\hline $\begin{array}{l}\text { Father smoking in conception } \\
\text { year }\end{array}$ & & & & \\
\hline 0 & 182 & 63.9 & 427 & 71.8 \\
\hline 1-14 CPD & 29 & 10.2 & 61 & 10.3 \\
\hline $15+\mathrm{CPD}$ & 72 & 25.3 & 105 & 17.6 \\
\hline FFQ version & & & & \\
\hline Full diet & 26 & 9.1 & 99 & 16.6 \\
\hline ‘Folate’ foods & 56 & 19.6 & 175 & 29.4 \\
\hline 'Folate, B6 and B12' foods & 203 & 71.2 & 321 & 53.9 \\
\hline
\end{tabular}

ACT, Australian Capital Territory; CPD cigarettes per day; FFQ; food frequency questionnaire; NSW, New South Wales; NT, Northern Territory; QLD, Queensland; SA, South Australia; TAS, Tasmania; VIC, Victoria; WA, Western Australia.

${ }^{a}$ European = at least 3 European grandparents; 50\% European = 2 European grandparents; At least 50\% non-European and not known if 50\% European = 2 non-European grandparents and ethnicity of other 2 grandparents unknown; 
Table 2: Range of paternal daily energy, dietary folate equivalents, B6 and B12 intakes in the six months before conception of index child

\begin{tabular}{lll}
\hline All versions of FFQ & Cases $(\mathrm{n}=285)$ & Controls(n= 595) \\
\hline Total energy $(\mathrm{kJ})$ & & \\
Minimum & 4186 & 4312 \\
Median & 9212 & 8967 \\
Maximum & 19045 & 17774 \\
Inter-quartile range & 203 & 183 \\
Energy Adjusted Dietary Folate Equivalents $(\mu \mathrm{g})$ & & \\
Minimum & 156 & 122 \\
Median & 420 & 437 \\
Maximum & 1143 & 1081 \\
Inter-quartile range & 3549 & 3557 \\
& & \\
\hline Restricted to FFQs with dietary B6 and B12 data & Cases $(\mathrm{n}=229)$ & Controls(n=420) \\
\hline Energy Adjusted Dietary B6 $(\mathrm{mg})$ & & \\
Minimum & 0.8 & 1.0 \\
Median & 1.6 & 1.6 \\
Maximum & 2.6 & 2.7 \\
Inter-quartile range & 0.3 & 0.3 \\
Energy Adjusted Dietary B12 $(\mu g)$ & & \\
Minimum & 1.4 & 2.2 \\
Median & 6.0 & 5.8 \\
Maximum & 15.3 & 14.5 \\
Inter-quartile range & 2.4 & 2.1 \\
\hline
\end{tabular}


Table 3: Odds ratios for paternal dietary and supplemental folate, B6 and B12 in the six months before conception of index child

\begin{tabular}{|c|c|c|c|}
\hline \multirow[b]{2}{*}{ All versions of FFQ } & Cases & Controls & OR (95\% CI) \\
\hline & $n=285$ & \multicolumn{2}{|l|}{$\mathrm{n}=595$} \\
\hline \multicolumn{4}{|l|}{ Energy Adjusted Dietary Folate } \\
\hline Equivalents & n (\%) & n (\%) & \\
\hline 390 and less & $118(41.4)$ & $198(33.3)$ & Reference \\
\hline$>390$ to 503 & $83(29.1)$ & $198(33.3)$ & $0.85(0.59,1.24)^{a}$ \\
\hline$>503 \mu g$ & $84(29.5)$ & 199 (33.4) & $0.87(0.58,1.29)^{a}$ \\
\hline \multicolumn{4}{|l|}{ Folic acid and/or vitamin B6 and/or } \\
\hline B12 supplement use & $24(8.4)$ & $46(7.7)$ & $1.37(0.78,2.40)^{a}$ \\
\hline \multicolumn{4}{|l|}{ Restricted to FFQs with dietary B6 } \\
\hline \multicolumn{4}{|l|}{ Energy Adjusted Dietary B6 } \\
\hline 1.52 and less & 82 (35.8) & $139(33.1)$ & Reference \\
\hline$>1.52$ to 1.71 & $79(34.5)$ & $142(33.8)$ & $0.72(0.47,1.12)^{b}$ \\
\hline$>1.85 \mathrm{mg}$ & $68(29.7)$ & $139(33.1)$ & $0.76(0.48,1.20)^{b}$ \\
\hline \multicolumn{4}{|l|}{ Energy Adjusted Dietary B12 } \\
\hline 5.20 and less & $68(29.7)$ & $139(33.1)$ & Reference \\
\hline$>5.20$ to 6.46 & $70(30.6)$ & $142(33.8)$ & $1.11(0.71,1.74)^{b}$ \\
\hline$>6.46 \mu \mathrm{g}$ & $91(39.7)$ & $139(33.1)$ & $1.51(0.97,2.36)^{b}$ \\
\hline \multicolumn{4}{|c|}{$\begin{array}{l}{ }^{a} \text {. Adjusted for birth order, best parental education, paternal age, paternal smoking in the } \\
\text { conception year, year of agreement and FFQ version, supplement use (folate, B6 or B12) } \\
\text { and matching variables (state, sex, age) }\end{array}$} \\
\hline \multicolumn{4}{|c|}{$\begin{array}{l}b \text {. Adjusted for birth order, best parental education, paternal age, paternal smoking in the } \\
\text { conception year, year of agreement and FFQ version, dietary folate, B6 and B12, } \\
\text { supplement use (folate, B6 or B12) and matching variables (state, sex, age) }\end{array}$} \\
\hline
\end{tabular}


Table 4: Odds ratios for paternal dietary and supplemental folate, B6 and B12 in the last six months before conception of index child, stratified by child's age at censoring date.

All versions of FFQ

Energy Adjusted Dietary Folate

$$
\text { Equivalents }
$$

390 and less

$>390$ to 503

$>503 \mu \mathrm{g}$

Restricted to FFQs with dietary B6 and B12 data

Energy Adjusted Dietary B6

1.52 and less

$>1.52$ to 1.71

$>1.85 \mathrm{mg}$

Age less than 5 years

$\begin{array}{ll}\text { Cases } & \text { Controls } \\ n=154 & n=326\end{array}$

n (\%) n (\%)

39 (33.1) 87 (26.7)

$35(26.0)$

$102(31.3$

$52(40.9)$

$137(42.0)$

$0.75(0.43,1.31)^{a}$

$1.12(0.67,1.88)^{a}$

$P$ value for trend $=0.59$

Age 5 years or more

$\begin{array}{ll}\text { Cases } & \text { Controls } \\ \mathrm{n}=103 & \mathrm{n}=226 \\ \mathrm{n}(\%) & \mathrm{n}(\%) \\ 67(51.1) & 89(41.3) \\ 43(32.8) & 77(35.7) \\ 21(16.0) & 60(23.0)\end{array}$

$n=126 \quad n=194$

$46(36.5)$

$44(34.9)$

36 (28.6)

$59(30.4)$
$68(35.1)$
$67(34.5)$

Reference

$0.82(0.45,1.49)^{b}$

$0.65(0.34,1.23)^{b}$

$P$ value for trend $=0.18$

$\mathrm{n}=103$

40 (38.8)

$27(26.2)$

$36(35.0)$

74 (32.7)

72 (31.9)

$n=226$

36 (28.6)

35 (27.8)

55 (43.7)

$\begin{array}{ll}32(31.1) & 75(33.2) \\ 35(34.0) & 68(30.1) \\ 36(35.0) & 83(36.7)\end{array}$

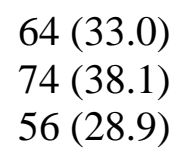

Reference

$0.93(0.50,1.74)^{b}$

$1.77(0.96,3.27)^{b}$

$P$ value for trend $=0.06$

OR (95\% CI)

\section{Reference}

$0.97(0.56,1.68)^{a}$

$0.63(0.32,1.24)^{a}$

$P$ value for trend $=0.23$

Interaction $p$ value $=$

$$
0.33
$$

Reference

$0.58(0.30,1.12)^{b}$

$1.03(0.53,2.01)^{b}$

$P$ value for trend $=0.99$

Interaction $p$ value $=$

$$
0.37
$$

Reference

$1.50(0.78,2.92)^{b}$

$1.46(0.75,2.86)^{b}$

$P$ value for trend $=0.11$

Interaction $p$ value $=$

$$
0.15
$$

${ }^{a}$. Adjusted for birth order, best parental education, paternal age, paternal smoking in the conception year, and FFQ version, supplement use (folate, B6 or B12) and matching variables (state, sex, age)

${ }^{b}$. Adjusted for birth order, best parental education, paternal age, paternal smoking in the conception year, year of agreement and FFQ version, dietary folate, B6 and B12, supplement use (folate, B6 or B12) and matching variables (state, sex, age) 
Table 5: Odds ratios for paternal dietary and supplemental folate, B6 and B12 in the six months before conception of index child, stratified by alcohol consumption

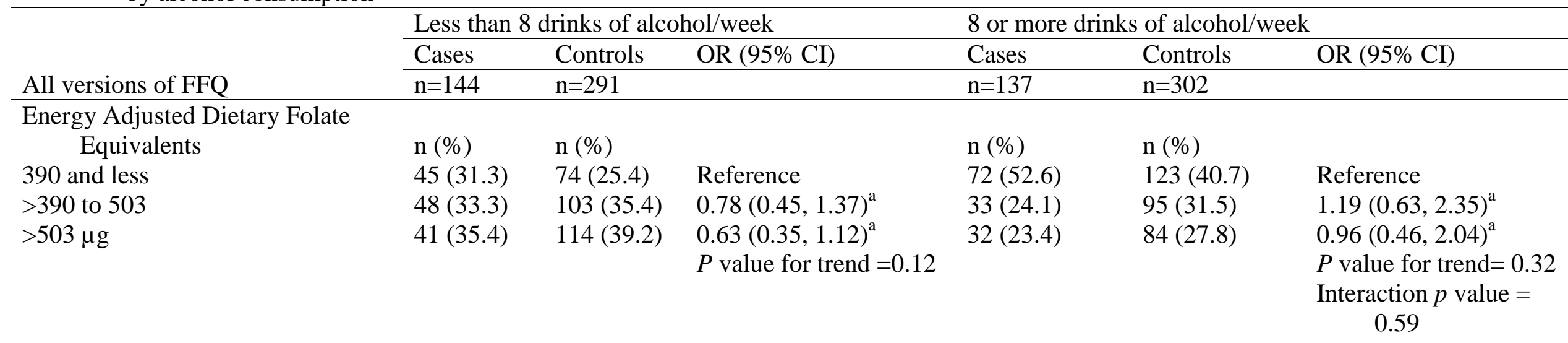

Restricted to FFQs with dietary B6

and B12 data

$n=126$

$\mathrm{n}=194$

$\mathrm{n}=103$

$n=226$

Energy Adjusted Dietary B6

1.52 and less

$>1.52$ to 1.71

$\begin{array}{ll}49(41.5) & 69(33.2) \\ 29(24.6) & 68(32.7) \\ 40(33.9) & 71(34.1)\end{array}$

Reference

$0.40(0.20,0.78)^{b}$

$41(37.6)$

(33.)

$73(34.8)$

Reference

$>1.85 \mathrm{mg}$

$P$ value for trend $=0.17$

$32(29.4) \quad 67(31.9)$

$1.20(0.63,2.26)^{\mathrm{b}}$

$1.02(0.51,2.04)^{\mathrm{b}}$

$P$ value for trend $=0.94$

Interaction $p$ value $=$

0.19

Energy Adjusted Dietary B12

5.20 and less

$>5.20$ to 6.46

$\begin{array}{ll}18(15.3) & 45(21.6) \\ 44(37.3) & 71(34.1) \\ 56(47.5) & 92(44.2)\end{array}$

Reference

$1.61(0.72,3.61)^{\mathrm{b}}$

48 (44.0)

93 (44.3)

26 (23.9)

$70(33.3)$

$1.59(0.73,3.50)^{\mathrm{b}}$

35 (32.1)

47 (22.4)

Reference

$P$ value for trend $=0.33$

. $86(0.46,1.63)^{\mathrm{b}}$

$1.64(0.85,3.18)^{\mathrm{b}}$

$P$ value for trend $=0.20$

Interaction $p$ value $=$

0.38

${ }^{a}$. Adjusted for birth order, best parental education, paternal age, paternal smoking in the conception year, year of agreement and FFQ version, supplement use (folate, B6 or B12) and matching variables (state, sex, age) 
FFQ Food frequency questionnaire

${ }^{b}$. Adjusted for birth order, best parental education, paternal age, paternal smoking in the conception year, year of agreement and FFQ version, dietary folate, B6 and B12, supplement use (folate, B6 or B12) and matching variables (state, sex, age) 
Supplementary Table 1: Odds ratios for paternal dietary and supplemental folate, in the six months before conception of index child, by food frequency questionnaire (FFQ) version

\begin{tabular}{|c|c|c|c|c|c|c|}
\hline & \multicolumn{3}{|c|}{ All versions of FFQ } & \multicolumn{3}{|c|}{ Versions of FFQs that contained B6 and B12 foods } \\
\hline & Cases & Controls & & Cases & Controls & \\
\hline & $n=285$ & $\mathrm{n}=595$ & OR $\left(95 \%\right.$ CI) ${ }^{a}$ & $n=229$ & $n=420$ & OR $\left(95 \%\right.$ CI) ${ }^{b}$ \\
\hline Energy Adjusted Dietary Folate & n (\%) & n (\%) & & $\mathrm{n}(\%)$ & $\mathrm{n}(\%)$ & \\
\hline 390 and less & $118(41.4)$ & $198(33.3)$ & Reference & $104(45.4)$ & $164(39.0)$ & Reference \\
\hline$>390$ to 503 & $83(29.1)$ & $198(33.3)$ & $0.85(0.59,1.24)^{a}$ & $63(27.5)$ & $139(33.1)$ & $0.82(0.52,1.27)$ \\
\hline$>503 \mathrm{mcg}$ & $84(29.5)$ & $199(33.4)$ & $0.87(0.58,1.29)^{a}$ & $62(27.1)$ & $117(27.6)$ & $0.86(0.53,1.37)$ \\
\hline
\end{tabular}

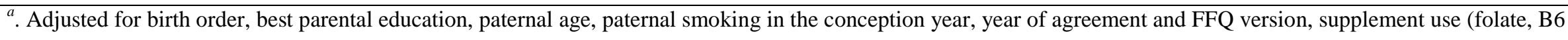
or B12) and matching variables (state, sex, age)

${ }^{b}$. Adjusted for birth order, best parental education, paternal age, paternal smoking in the conception year, year of agreement and FFQ version, dietary folate, B6 and B12, supplement use (folate, B6 or B12) and matching variables (state, sex, age)

FFQ Food frequency questionnaire 